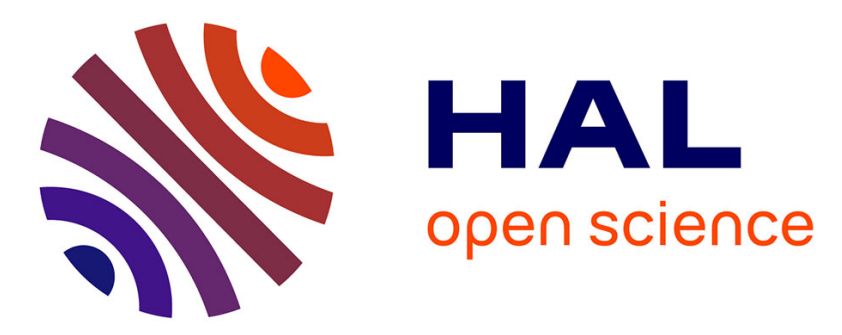

\title{
High-speed interband cascade laser absorption sensor for multiple temperatures in $\mathrm{CO} 2$ rovibrational non-equilibrium
}

Christopher Jelloian, Nicolas Minesi, Raymond Spearrin

\section{- To cite this version:}

Christopher Jelloian, Nicolas Minesi, Raymond Spearrin. High-speed interband cascade laser absorption sensor for multiple temperatures in CO2 rovibrational non-equilibrium. AIAA SCITECH 2022 Forum, Jan 2022, San Diego, France. 10.2514/6.2022-2398 . hal-03527547

\section{HAL Id: hal-03527547 \\ https://hal.science/hal-03527547}

Submitted on 18 Feb 2022

HAL is a multi-disciplinary open access archive for the deposit and dissemination of scientific research documents, whether they are published or not. The documents may come from teaching and research institutions in France or abroad, or from public or private research centers.
L'archive ouverte pluridisciplinaire HAL, est destinée au dépôt et à la diffusion de documents scientifiques de niveau recherche, publiés ou non, émanant des établissements d'enseignement et de recherche français ou étrangers, des laboratoires publics ou privés. 


\title{
High-speed interband cascade laser absorption sensor for multiple temperatures in $\mathrm{CO}_{2}$ rovibrational non-equilibrium
}

\author{
Christopher C. Jelloian*, Nicolas Q. Minesi ${ }^{\dagger}$, and R. Mitchell Spearrin ${ }^{\ddagger}$ \\ University of California, Los Angeles (UCLA), Los Angeles, CA 90095, USA
}

\begin{abstract}
An RF-diplexed laser absorption technique is employed to resolve spectral transitions of $\mathrm{CO}_{2}$ in the mid-infrared at $\mathrm{MHz}$ rates to infer non-equilibrium temperatures of rotation and vibration. A distributed feedback interband cascade laser (DFB-ICL) resolves 7 transitions within the $\mathrm{CO}_{2}$ fundamental asymmetric stretch band near $4.19 \mu \mathrm{m}$, representing a range of rotational and vibrational energies. Non-equilibrium spectra are resolved at $\mathrm{MHz}$ rates and fit with a two-temperature model for line intensities. The sensor is demonstrated on a high enthalpy shock tube, targeting temperatures between 1250 - $3500 \mathrm{~K}$ and sub-atmospheric pressures in various $\mathrm{CO}_{2}$ - Ar gas mixtures. Tests have shown that this sensor provides sensitive temperature measurements with 1- $\mu$ s resolution over a wide range of conditions relevant to Mars entry radiation. Vibrational relaxation times on the order of $10 \mu$ s are resolved and compared to existing models.
\end{abstract}

\section{Nomenclature}

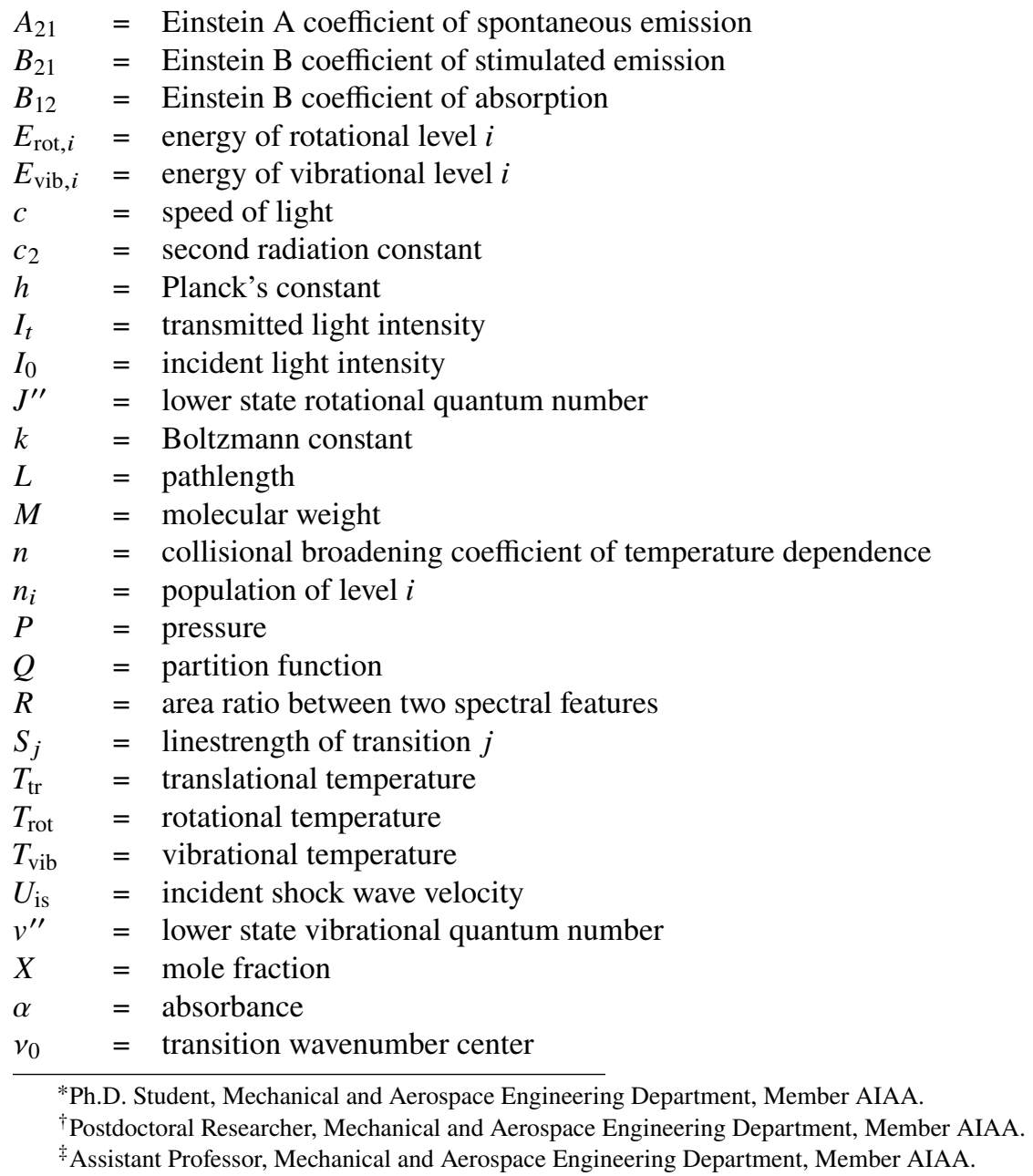




$\begin{array}{ll}\Delta v_{C} & =\text { collisional (Lorentzian) FWHM } \\ \Delta v_{D} & =\text { Doppler (Gaussian) FWHM } \\ \phi & =\text { lineshape function } \\ \gamma_{A-B} & =\text { collisional broadening coefficient } \\ \mathcal{A}_{i} & =\text { absorbance area of transition } i\end{array}$

\section{Introduction}

$\mathrm{T}$ HERMAL non-equilibrium of $\mathrm{CO}_{2}$ has been studied for a variety of applications including $\mathrm{CO}_{2}$ plasma modeling and planetary entry on Venus and Mars. As an entry vehicle encounters a planetary atmosphere, the bow shock rapidly excites the translational and rotational modes of the gas whereas the vibrational energy mode of the gas lags behind [1]. As the gas expands around the shoulder of the entry vehicle, the translational and rotational temperatures drop and the gas undergoes non-equilibrium recombination. Radiative heating can be significant on both the fore and aft heatshields depending on the entry velocity. If the energy of the shock wave is high enough, dissociation breaks the $\mathrm{CO}_{2}$ to form $\mathrm{CO}$ and atomic $\mathrm{O}$. Reaction rates for $\mathrm{CO}_{2}$ dissociation are extensively studied [2-5], but these studies usually do not account for thermal non-equilibrium effects $\left(T_{\text {tr }} \neq \mathrm{T}_{\text {rot }} \neq \mathrm{T}_{\text {vib }}\right)$ typically encountered during entries. A multi-temperature or state-to-state kinetic model can be employed to more rigorously analyze the shock layer.

Recent Mars entry studies [6, 7] have highlighted the need to better quantify the $\mathrm{CO}_{2}$ non-equilibrium radiation in the mid-wave infrared to lower uncertainties in radiative heating rates experienced on the fore and aft heat shields of the thermal protection system (TPS). In the backshell region of the Mars entry flow, $\mathrm{CO}+\mathrm{O}$ recombine to form a significant amount of vibrationally excited $\mathrm{CO}_{2}$ which then radiates and heats up the backshell. Cruden et al. [6] have investigated this phenomena with an emission spectroscopy technique to spectrally and spatially resolve radiance behind incident shock waves in pure $\mathrm{CO}_{2}$ at shock velocities up to $7.5 \mathrm{~km} / \mathrm{s}$ in the Electric Arc Shock Tube (EAST) facility at NASA Ames. They noted that the measured radiance can not be predicted by a single mechanism over the range of conditions tested.

Recent modeling efforts have sought to better understand the complex vibration and dissociation dynamics of $\mathrm{CO}_{2}$ with a state-to-state model approach. Vargas et al. [8] have published a mechanism combining chemical rates available in literature and rates of vibrational energy exchange determined from forced harmonic oscillator theory. In total, the model includes 11 species, 2 electronic states of $\mathrm{O}$ and $\mathrm{CO}_{2}, 201$ vibrational levels of $\mathrm{CO}_{2}$, and 22,569 reactions. This model represents one of the most comprehensive approaches to modeling $\mathrm{CO}_{2}$ dissociation and the authors note that "completely adequate modeling of $\mathrm{CO}_{2}$ state-to-state processes is an endeavor still out of reach [and] will require extensive theoretical and experimental work". In a recent study of Johnston et al. [9], the non-equilibrium kinetic model of Park et al. [10] was improved and adequately predicted the non-equilibrium radiation in a series of experiments conducted at EAST. However, this model failed to predict the $\mathrm{CO}_{2}$ radiation in the range of velocity explored by Cruden et al. [6]. Therefore, there is a need for high resolution, non-equilibrium measurements of $\mathrm{CO}_{2}$ dissociation/recombination to better inform models in the entry environment.

In this study, an optical diagnostic is developed for measurements of rotational and vibrational temperature of $\mathrm{CO}_{2}$. This work builds on similar absorption techniques demonstrated to partially resolve non-equilibrium temperatures in shock tube and plasma discharge environments $\left(\mathrm{T}_{\text {tr }}\right.$ of $\mathrm{CO}_{2} \& \mathrm{CO}$ [11], and $\mathrm{T}_{\mathrm{rot}} \& \mathrm{~T}_{\text {vib }}$ of $\mathrm{CO}_{2}$ [12]) and follows directly from a prior effort by our research group demonstrating a sensor capable of resolving $\mathrm{T}_{\mathrm{tr}}, \mathrm{T}_{\text {rot }}$, and $\mathrm{T}_{\mathrm{vib}}$ in shock-heated $\mathrm{CO}$ [13]. The sensor can be deployed in various ground test facilities (such as arcjets or hypersonic wind tunnels) to quantitatively characterize and better constrain models and sub-models of the thermal dissociation and recombination of $\mathrm{CO}_{2}$ encountered during Mars entry.

\section{Methods and Theory}

Laser absorption spectroscopy (LAS) is utilized to infer energy mode-specific temperatures from spectrally-resolved light attenuation in the mid-wave infrared. Key governing equations and concepts are briefly discussed in this section as LAS theory is well-detailed in literature [14]. The Beer-Lambert law, shown in Eq. 11 relates the spectral absorbance $\alpha$ at frequency $v$ to thermophysical gas properties (temperature, pressure, velocity, etc.) via incident and transmitted light intensities, $I_{0}$ and $I_{t}$, respectively.

$$
\alpha(v)=-\ln \left(\frac{I_{t}}{I_{0}}\right)_{v}=S_{j}\left(T_{\mathrm{rot}}, T_{\mathrm{vib}}\right) \rho X_{A} L \phi_{j}\left(v, T_{\mathrm{tr}}, P, X_{A}\right)
$$


$\rho\left[\right.$ molec $\left.\cdot \mathrm{cm}^{-3}\right]$ is the number density, $X_{A}$ is the mole fraction of the absorbing species $A, L[\mathrm{~cm}]$ is the pathlength, $S_{j}\left(T_{\text {rot }}, T_{\mathrm{vib}}\right)\left[\mathrm{cm}^{-1} /\left(\mathrm{molec} \cdot \mathrm{cm}^{-2}\right)\right]$ is the linestrength of rovibrational transition $j$ at rotational temperature $T_{\text {rot }}[\mathrm{K}]$ and vibrational temperature $T_{\text {vib }}[\mathrm{K}]$, and $\phi_{j}\left(\nu, T_{\mathrm{tr}}, P, X_{A}\right)[\mathrm{cm}]$ is the lineshape function.

In this study, scanned-wavelength laser absorption spectroscopy is utilized to resolve $\phi_{j}$, which is modeled using the Voigt profile. The Voigt lineshape captures the collisional and Doppler broadening effects of the features with a convolution of Lorentzian and Gaussian profiles. The value of $\phi_{j}$ at the transition linecenter $v_{j, 0}$ is expressed in Eq. 2 , where $a$ is the spectral damping parameter and $\Delta v_{D}\left[\mathrm{~cm}^{-1}\right]$ and $\Delta v_{C}\left[\mathrm{~cm}^{-1}\right]$ are the Doppler and collisional linewidth contributions, respectively.

$$
\begin{gathered}
\phi_{j}\left(v_{j, 0}\right)=\frac{2}{\Delta v_{D}} \sqrt{\frac{\ln 2}{\pi}} \exp \left(a^{2}\right)[1-\operatorname{erf}(a)] \\
a=\frac{\sqrt{\ln 2} \Delta v_{C}}{\Delta v_{D}}
\end{gathered}
$$

The Doppler linewidth depends on translational temperature $T_{\text {tr }}$, the molecular weight $M\left[\mathrm{~g} \cdot \mathrm{mol}^{-1}\right]$ of the absorbing species, and the transition linecenter $v_{J, 0}\left[\mathrm{~cm}^{-1}\right]$ as indicated in Eq. 4 Collisional linewidth scales with pressure and the mole fraction weighted broadening coefficient of collision partner $B$ with absorbing molecule $A$, as shown in Eq.5. Additionally, the broadening coefficient $\left(\gamma_{A-B}\right)$ is typically modeled by implementing a power law, as shown in Eq. 6. where $T_{0}[\mathrm{~K}]$ is a reference temperature and $n$ is the temperature exponent. For this study, collisional broadening coefficients and temperature exponents for $\mathrm{CO}_{2}-\mathrm{CO}_{2}$ and $\mathrm{CO}_{2}-\mathrm{Ar}$ were taken from Lee et al. [15], and the HITEMP database [16].

$$
\begin{gathered}
\Delta v_{D}=v_{J, 0}\left(7.1623 \times 10^{-7}\right) \sqrt{\frac{T_{\mathrm{tr}}}{M}} \\
\Delta v_{C}=P \sum_{B} X_{B} 2 \gamma_{A-B} \\
\gamma_{A-B}\left(T_{\mathrm{Tr}}\right)=\gamma_{A-B}\left(T_{0}\right)\left(\frac{T_{0}}{T_{\mathrm{Tr}}}\right)^{n} \\
\mathcal{A}_{j}=S_{j}\left(T_{\mathrm{rot}}, T_{\mathrm{vib}}\right) \rho X_{A} L \\
R=\frac{\mathcal{A}_{1}}{\mathcal{A}_{2}}=\frac{S_{1}\left(T_{\mathrm{rot}}, T_{\mathrm{vib}}\right)}{S_{2}\left(T_{\mathrm{rot}}, T_{\mathrm{vib}}\right)}
\end{gathered}
$$

\section{A. Line Selection}

To resolve non-equilibrium temperatures of $\mathrm{CO}_{2}, 7$ spectral features are targeted for measurement in the mid-infrared vibrational bands near $4.19 \mu \mathrm{m}$. These lines were selected for strong absorbance signals over a wide range of temperatures $(1500-3000 \mathrm{~K})$. The energy level spacing is sufficient for sensitive rotational and vibrational temperature measurements above $3000 \mathrm{~K}$. The spectrum is shown in Fig. 1 Two vibrational levels are probed. The $\mathrm{R}(58 \mathrm{e})$ line is from the ground vibrational level $\left(00^{0} 0(1)\right)$ and the $\mathrm{R}(103 \mathrm{e}), \mathrm{R}(104 \mathrm{f}), \mathrm{R}(105 \mathrm{e}), \mathrm{R}(106 \mathrm{f})$, and $\mathrm{R}(140 \mathrm{f})$ transitions lie in the first excited bending mode $\left(01^{1} 0(1)\right)$.

\section{B. Experimental Setup}

The optical and experimental setup is shown in Fig. 2. An interband cascade laser is used to probe the selected rovibrational lines of the asymmetric stretch fundamental band of $\mathrm{CO}_{2}$ near $4.19 \mu \mathrm{m}$. Current through the laser is modulated at $1 \mathrm{MHz}$ using a bias tee circuit (or RF-diplexer). A 2-inch germanium etalon is used to transform light intensity signals from the time domain to the wavenumber domain. Background and etalon signals are recorded before each test. A narrowband filter and iris are used to mitigate the emission signal on the catch side of the sensor, and a focusing lens collects the light onto a high bandwidth ( 200 MHz) photovoltaic detector.

The high enthalpy shock tube (HEST) at UCLA was used to near-instantaneously heat various $\mathrm{CO}_{2}-\mathrm{Ar}$ gas mixtures and generate a well known set of equilibrium conditions behind incident shock waves with velocities up to $2.9 \mathrm{~km} / \mathrm{s}$. 

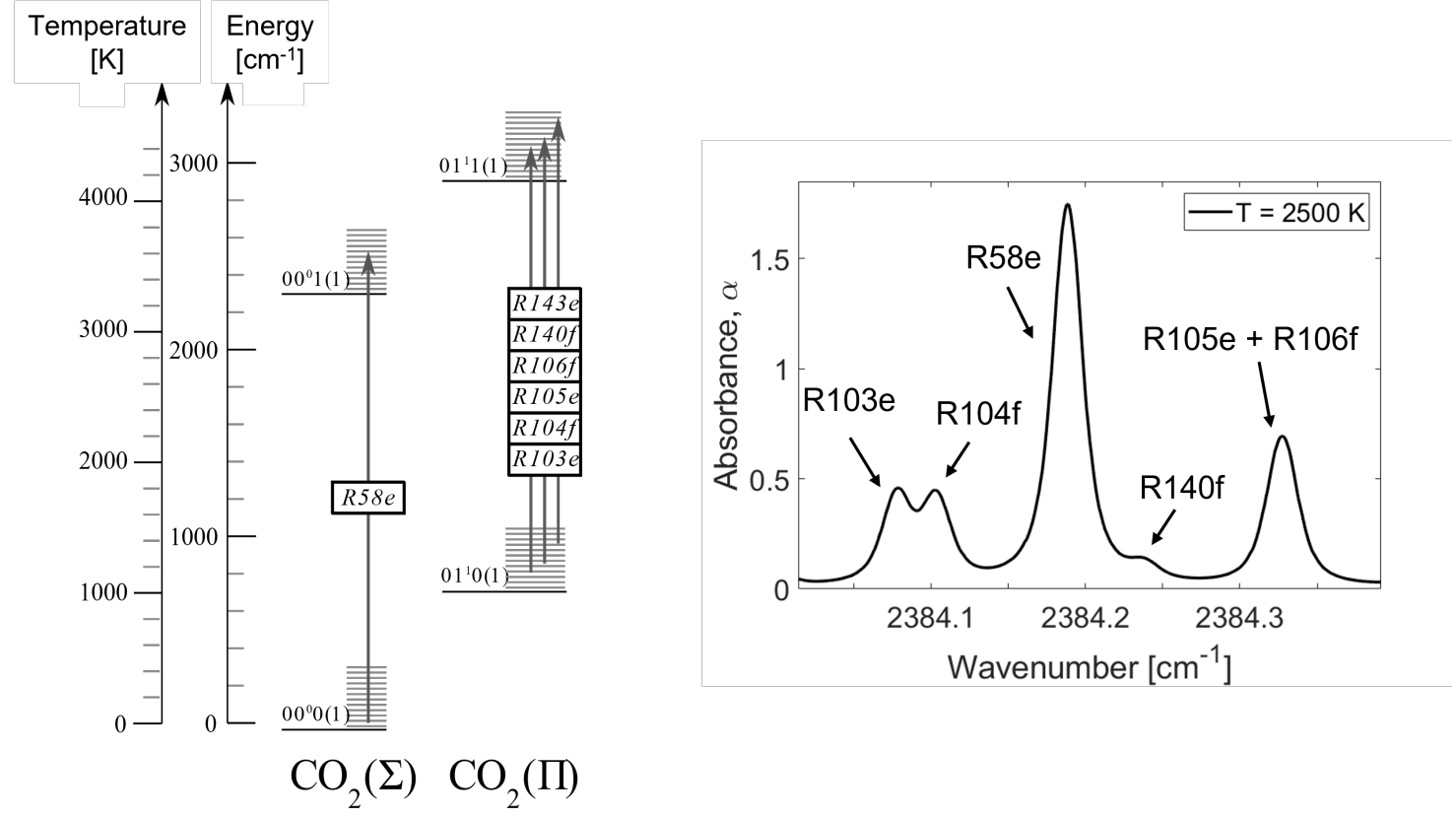

Fig. 1 (left) Energy level diagram of $\mathrm{CO}_{2}$ molecule showing levels of interest in this study (rotational energy levels not-to-scale). Note the $\mathrm{CO}_{2}$ multiplicity $(\Sigma$ or $\Pi)$ varies with the bending excitation. (right) Simulated spectra at $2500 \mathrm{~K}\left(20 \% \mathrm{CO}_{2}, 0.2 \mathrm{~atm}\right)$ using the HITEMP database [16].

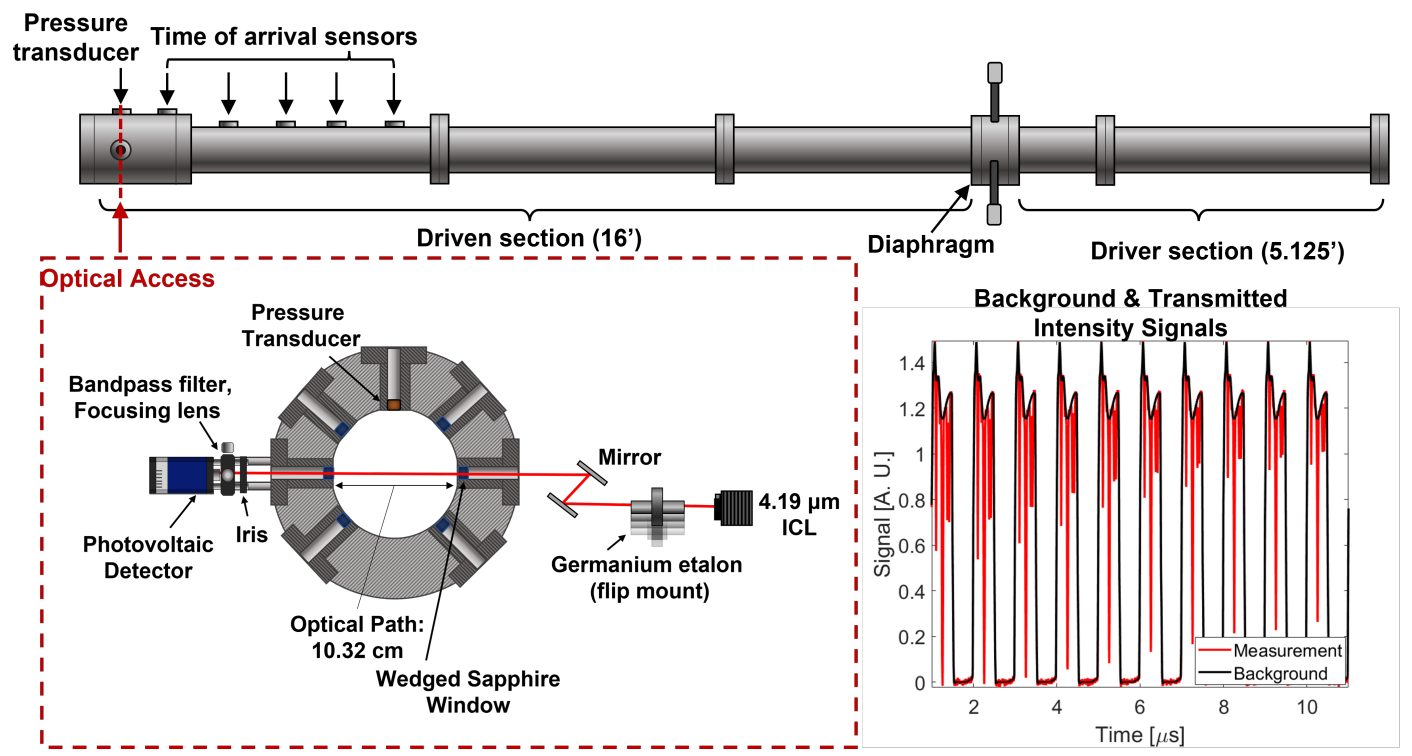

Fig. 2 (top) Shock tube schematic. (left) Sensor layout through the optical access location $2 \mathrm{~cm}$ from the endwall. (right) Background and transmitted light intensity signals during incident shock test. Note the transient intensity in the measurement signal.

$\mathrm{CO}_{2}$ concentrations ranged from $2 \%-100 \%$. The tube consists of a $5.125 \mathrm{ft}$ cold gas driver and a $16 \mathrm{ft}$ driven section. 5 piezoelectric transducers are used to measure the shock velocity. Optical access and a high-speed pressure transducer (Kistler 601B1) are located $2 \mathrm{~cm}$ from the endwall. Before filling the tube with test gas, a turbopump is used to achieve 
an ultimate vacuum pressure on the order of $100 \mathrm{~s}$ of $\mu$ torr. Leak rates are in the range $0.1-1 \mathrm{mtorr} / \mathrm{min}$ and are measured with a Baratron manometer (627D) before each test.

In this work, the laser chip was modulated using the RF-diplexed system described in [17] with a square waveform. This type of modulation maximizes the signal intensity, and hence optimizes the signal to noise ratio (SNR) during the spectral scan. Also, the laser chip experiences the greatest temperature difference between the up and down scans, which provides the highest scan-depth possible for a given amplitude of current modulation. The laser intensity scan is shown in Fig. 2, which corresponds to a scan depth of approximately $0.4 \mathrm{~cm}^{-1}$ at $1 \mathrm{MHz}$ repetition rate. Additional details on improving the scan-depth using arbitrary waveforms are given in [18].

\section{Data Interpretation}

In order to relate the measured absorbance areas of the resolved spectrum to non-equilibrium temperatures through Eq. 8, an accurate linestrength model is needed. The fundamental definition of linestrength accounting for stimulated emission is shown in Eq. 9. $B_{12}$ and $B_{21}$ are the Einstein coefficients for absorption and stimulated emission, which are calculated from the Einstein A coefficient $\left(A_{21}\right)$ tabulated in HITEMP [16], $h v$ is the energy of the transition, $c$ is the speed of light, $n_{1}$ and $n_{2}$ are the populations of the lower and upper levels, respectively. By assuming separable Boltzmann populations over rotation and vibration, Eq. 10 can be derived from Eq. 9 where $g_{2}$ is the upper level degeneracy, $E_{\mathrm{rot}, 1}$ and $E_{\mathrm{vib}, 1}$ are the rotational and vibrational energies of the lower state, $E_{\mathrm{rot}, 2}$ and $E_{\mathrm{vib}, 2}$ are the rotational and vibrational energies of the upper state, $Q_{\text {rot }}$ and $Q_{\text {vib }}$ are the partition functions of rotation and vibration. It is important to note that $\mathrm{CO}_{2}$ has 3 vibrational modes; symmetric stretch (ss), doubly degenerate bending (bend), and asymmetric stretch (as) that may be at separate temperatures $\left(\mathrm{T}_{s s} \neq \mathrm{T}_{\text {bend }} \neq \mathrm{T}_{a s}\right)$. For the lines selected in this study, no upper level symmetric or asymmetric stretch states are probed, therefore only 1 vibrational temperature is assumed over all vibrational modes.

A two temperature model is used to fit the seven spectral features shown in Fig. 3. The collisional broadening is floated over the low J number (R58), mid J number (R103-R106), and high J number (R140, R143) transitions. By grouping the collisional broadening terms based on $\mathrm{J}$ number, the uncertainty of the lineshape in the blended spectral features is mitigated, because the broadening coefficients should be very similar. Additionally, the R(58) feature is large compared to the other spectral features in these tests and tends to dominate the fitting routine. Therefore, a weight is applied to the cost function in the fitting routine, to ensure the small spectral feature is adequately captured. On a majority of the tests, the smallest spectral feature is the $\mathrm{R}(140)$ line. On the low temperature tests $(\mathrm{T}<1500 \mathrm{~K})$ the $\mathrm{R}(140)$ feature is not present due to low population in this high rotational level, therefore the weight function was applied to the $\mathrm{R}(103)$ and $\mathrm{R}(104)$ features. The weight function that was applied on all tests is shown in Eq. 11 where $\alpha_{\text {peak, max }}$ is the $\mathrm{R}(58)$ absorbance peak and $\alpha_{\text {peak, min }}$ is the $\mathrm{R}(140)$ peak if visible or the $\mathrm{R}(103), \mathrm{R}(104)$ absorbance peaks.
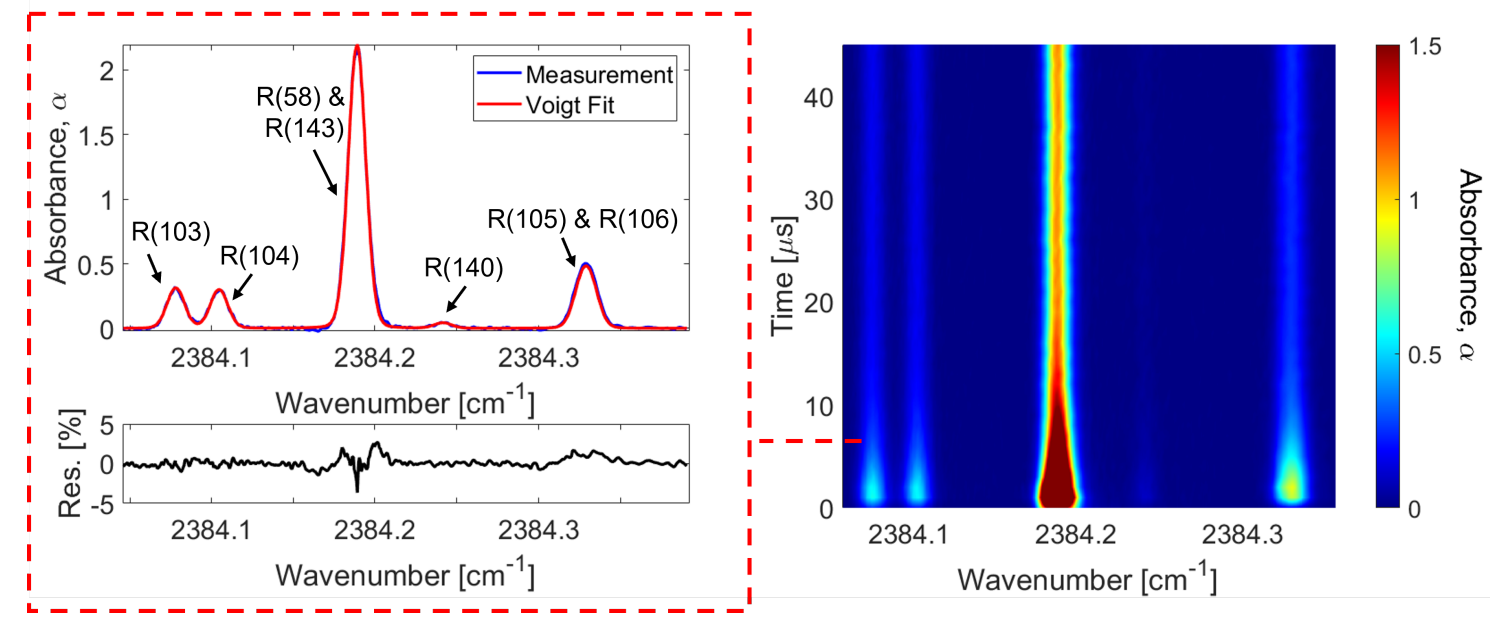

Fig. 3 (left) Voigt Fit of the spectra at $\mathrm{t}=7 \mu \mathrm{s}$ into the test. (right) $2 \mathrm{D}$ map of absorbance versus time and wavenumber. $20 \% \mathrm{CO}_{2} / \mathrm{Ar}$ shock, $\mathrm{U}_{i s}=1606 \pm 11 \mathrm{~m} / \mathrm{s}, \mathrm{T}_{e q}=2129 \pm 25 \mathrm{~K}, \mathbf{P}_{e q}=28.4 \pm 0.4 \mathrm{mbar}$.

$$
S_{j}=\left(n_{1} B_{12}-n_{2} B_{21}\right) \frac{h v}{c}
$$




$$
\begin{gathered}
S_{j}=\frac{A_{21} g_{2}}{8 \pi v^{2} c Q_{\mathrm{rot}}\left(T_{\mathrm{rot}}\right) Q_{\mathrm{vib}}\left(T_{\mathrm{vib}}\right)}\left[\exp \left(\frac{-c_{2} E_{\mathrm{rot}, 1}}{T_{\mathrm{rot}}}\right) \exp \left(\frac{-c_{2} E_{\mathrm{vib}, 1}}{T_{\mathrm{vib}}}\right)-\exp \left(\frac{-c_{2} E_{\mathrm{rot}, 2}}{T_{\mathrm{rot}}}\right) \exp \left(\frac{-c_{2} E_{\mathrm{vib}, 2}}{T_{\mathrm{vib}}}\right)\right] \\
W=0.7 \frac{\alpha_{\text {peak }, \text { max }}}{\alpha_{\text {peak, } \text { min }}}
\end{gathered}
$$

\section{Results}

Experiments were conducted to determine the range, accuracy and precision of the sensor. Incident shock wave velocities ranged from $1.1-2.9 \mathrm{~km} / \mathrm{s}$ generating equilibrium temperatures from $1250-3460 \mathrm{~K}$ and equilibrium pressures from $0.03-0.17$ atm. From the normal shock relations solver [19], the measured temperatures after relaxation and equilibrium temperatures can be compared to validate the sensor and method. The deviation of the measured temperatures with the simulated shock temperature from theory [19], is shown in Fig. 4. In this figure, the residual is the root-mean-square (RMS) error defined as in Eq. 12 where $T_{x}$ is either $T_{\text {rot }}$ or $T_{\text {vib }}$, and $\mathrm{N}$ the number of data points in the equilibrium region. The RMS error is found to be $<3 \%$ for $T_{\text {rot }}$ and $<2 \%$ for $T_{\text {vib }}$. The average standard deviation $(2 \sigma)$ of the measured temperatures in the equilibrium region of each test is found to be $86 \mathrm{~K}$ for $T_{\text {rot }}$ and $46 \mathrm{~K}$ for $T_{\mathrm{vib}}$.

$$
R M S=\frac{1}{N} \sqrt{\sum_{i=1}^{N}\left(T_{x, i}-T_{e q}\right)^{2}}
$$

Vibrational relaxation can be visualized in the spectra measurements by the depopulation of the low vibrational states. For instance, in Fig. 3 this effect is especially visible for the R58 line and lasts for approximately $20 \mu$ s. Note this signal decrease is not due to dissociation because the temperature of the test $(2129 \pm 25 \mathrm{~K})$ is well below that needed to initiate dissociation (above $3000 \mathrm{~K}$ ). After the first $20 \mu \mathrm{s}$, the width and area of the lines reach steady state which indicates that the rovibrational populations are at thermal equilibrium. The time resolution of the presented sensor enables the measurement of such short vibrational relaxation times. The increase of the vibrational temperature in time can be fit with an exponential function. Two examples are shown in Fig. 5] at low and high temperature shocks $\left(T_{5}=1250 \mathrm{~K}\right.$ and $\left.T_{5}=2800 \mathrm{~K}\right)$. For the test cases in this work, relaxation times were found to be bounded by the Park [10] and Simpson [20] models.
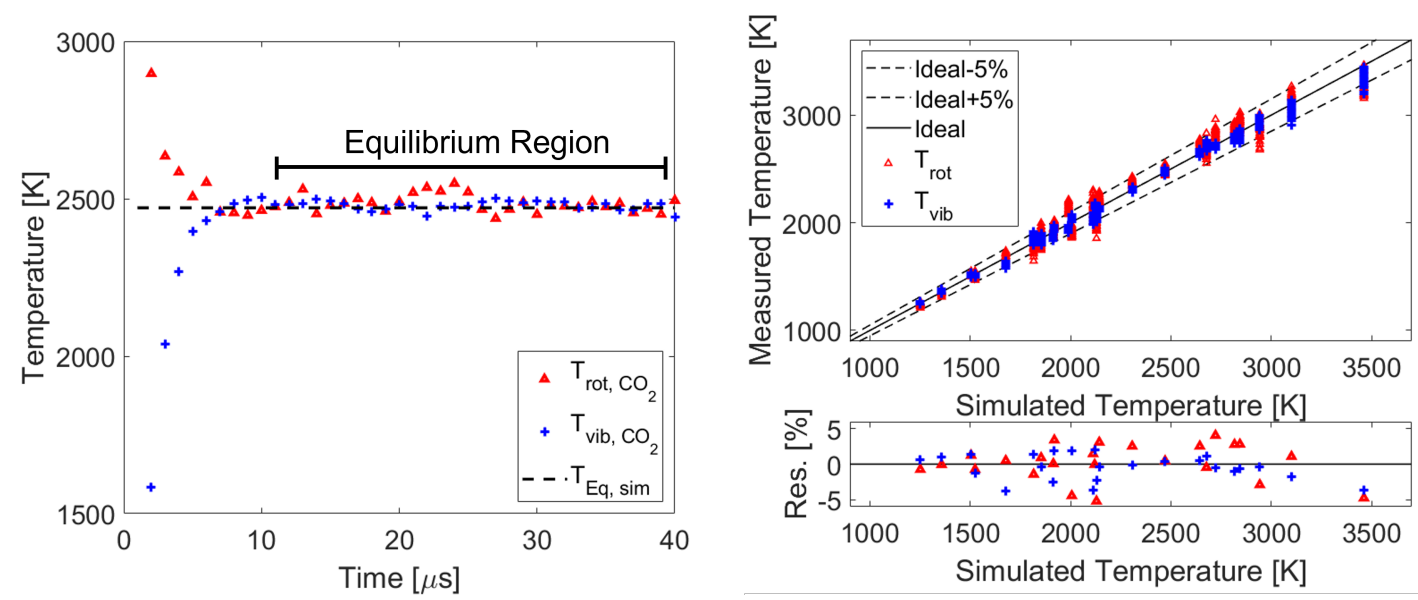

Fig. 4 (left) Time resolved temperatures. Note the rovibrational equilibrium reached at $\mathrm{t}>10 \mu \mathrm{s}$. (right) Measured equilibrium temperatures compared to normal shock relations solver [19]. Temperature ranges from 1250 - $3470 \mathrm{~K}$.

Rigorous uncertainty analysis of the results is the subject of ongoing work, however a few points are discussed. The two vibrational levels of $\mathrm{CO}_{2}$ probed in this study are the lowest lying vibrational states and are found to be sensitive up to approximately $3000 \mathrm{~K}$. At higher temperatures $(\mathrm{T}>3000 \mathrm{~K})$ it is difficult to separate dissociation from a vibrational 

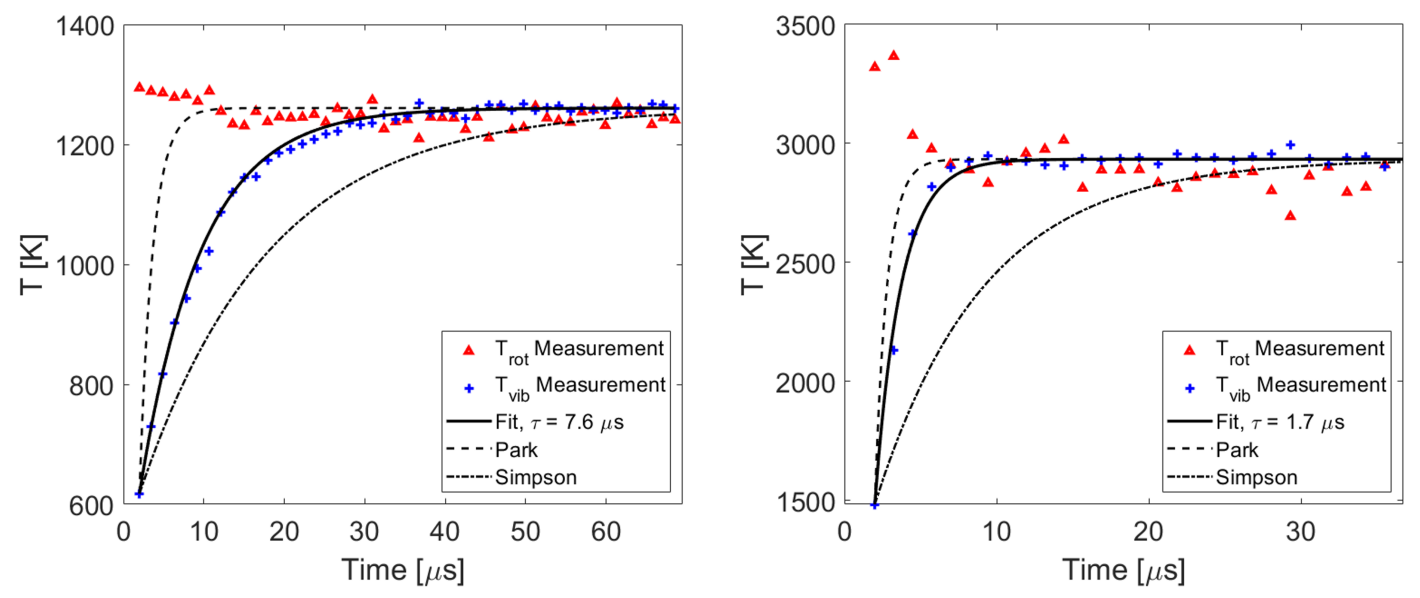

Fig. 5 (left) Time resolved temperatures. $2 \% \mathrm{CO}_{2}$ - Ar test case, $\mathrm{U}_{i s}=1061 \pm 6 \mathrm{~m} / \mathrm{s}$. (right) $20 \% \mathrm{CO}_{2}-\mathrm{Ar}$ test case, $\mathrm{U}_{i s}=1941 \pm 16 \mathrm{~m} / \mathrm{s}$.

temperature increase in this absorbance spectrum as both cause the overall magnitude of the signal to decrease. This can be solved by probing higher vibrational states of $\mathrm{CO}_{2}$. Lastly, the $\mathrm{R}(140)$ feature of $\mathrm{CO}_{2}$ is small and is most sensitive to rotational temperature. A few tests exhibit noise that can be attributed to low absorbance on this line and can be mitigated using mixtures with higher concentration of $\mathrm{CO}_{2}$.

\section{Conclusions}

A mid-IR laser absorption sensor for probing rotational and vibrational temperatures of $\mathrm{CO}_{2}$ has been developed and shown to yield quantitative results for shock velocities between $1.1 \mathrm{~km} / \mathrm{s}-2.9 \mathrm{~km} / \mathrm{s}$ in $\mathrm{CO}_{2}$-Ar gas mixtures. Pressure and equilibrium temperature conditions ranged from $0.03-0.17$ atm and $1250-3470 \mathrm{~K}$. This sensing method probes three distinct ranges of rotational quantum number $(\mathrm{J}=58,103-106$, and 140) providing a sensitive rotational temperature measurement over a range of conditions and probes two distinct vibrational states of $\mathrm{CO}_{2}$ (ground and first excited bending mode) providing a sensitive vibrational temperature measurement. The high effective precision, accuracy, and temporal resolution $(1 \mu \mathrm{s})$ of this sensor as shown in Fig. 4 demonstrates its potential for use to investigate the complex vibration - dissociation dynamics of $\mathrm{CO}_{2}$ and is the subject of ongoing efforts.

\section{Acknowledgments}

The authors acknowledge Megan E. MacDonald and Brett Cruden for the support throughout this project. Nicolas Q. Minesi acknowledges support from an Early Career Faculty grant from NASA's Space Technology Research Grants Program awarded to R. Mitchell Spearrin. Christopher C. Jelloian is supported by a NASA Space Technology Research Fellowship.

\section{References}

[1] Vincenti, W. G., and Kruger, C. H., Introduction to Physical Gas Dynamics, $2^{\text {nd }}$ ed., John Wiley \& Sons, Inc., New York, 1967.

[2] Burmeister, M., and Roth, P., "ARAS measurements on the thermal decomposition of CO2 behind shock waves," AIAA Journal, Vol. 28, No. 3, 1990, pp. 402-405. https://doi.org/10.2514/3.10406 URL https://arc.aiaa.org/doi/10.2514/3.10406

[3] Oehlschlaeger, M. A., Davidson, D. F., and Jeffries, J. B., "Temperature measurement using ultraviolet laser absorption of carbon dioxide behind shock waves," Applied Optics, Vol. 44, No. 31, 2005, p. 6599. https://doi.org/10.1364/AO.44.006599

[4] Saxena, S., Kiefer, J. H., and Tranter, R. S., "Relaxation, incubation, and dissociation in CO2," Journal of Physical Chemistry A, Vol. 111, No. 19, 2007, pp. 3884-3890. https://doi.org/10.1021/jp066717b

[5] Davies, W. O., "Carbon dioxide dissociation at $6000^{\circ}$ to $11000^{\circ} \mathrm{K}$," The Journal of Chemical Physics, Vol. 43, No. 8, 1965, pp. 2809-2818. https://doi.org/10.1063/1.1697214 
[6] Cruden, B. A., Prabhu, D. K., and Brandis, A. M., "Measurement and characterization of mid-wave infrared radiation in CO2 shocks," AIAA AVIATION 2014 -11th AIAA/ASME Joint Thermophysics and Heat Transfer Conference, American Institute of Aeronautics and Astronautics Inc., 2014. https://doi.org/10.2514/6.2014-2962

[7] Brandis, A. M., Saunders, D. A., Johnston, C. O., Cruden, B. A., and White, T. R., "Radiative heating on the after-body of Martian entry vehicles," Journal of Thermophysics and Heat Transfer, Vol. 34, American Institute of Aeronautics and Astronautics Inc., 2020, pp. 66-77. https://doi.org/10.2514/1.T5613.

[8] Vargas, J., Lopez, B., and Lino Da Silva, M., "Heavy Particle Impact Vibrational Excitation and Dissociation Processes in CO2," Journal of Physical Chemistry A, Vol. 125, No. 2, 2021, pp. 493-512. https://doi.org/10.1021/acs.jpca.0c05677

[9] Johnston, C., Brandis, A., and Sutton, K., "Shock Layer Radiation Modeling and Uncertainty for Mars Entry," 43rd AIAA Thermophysics Conference, American Institute of Aeronautics and Astronautics, Reston, Virigina, 2012 , pp. 1-43. https://doi.org/10.2514/6.2012-2866. URL https://arc.aiaa.org/doi/10.2514/6.2012-2866

[10] Park, C., Howe, J. T., Jaffe, R. L., and Candler, G. V., "Review of chemical-kinetic problems of future NASA missions, II: Mars entries," Journal of Thermophysics and Heat Transfer, Vol. 8, No. 1, 1994, pp. 9-23. https://doi.org/10.2514/3.496

[11] Macdonald, M. E., Brandis, A. M., and Cruden, B. A., "Temperature and CO number density measurements in shocked CO and CO2 via tunable diode laser absorption spectroscopy," 2018 Joint Thermophysics and Heat Transfer Conference, 2018, pp. 1-23. https://doi.org/10.2514/6.2018-4067

[12] Klarenaar, B. L. M., Engeln, R., van den Bekerom, D. C. M., van de Sanden, M. C. M., Morillo-Candas, A. S., and Guaitella, O., "Time evolution of vibrational temperatures in a CO 2 glow discharge measured with infrared absorption spectroscopy," Plasma Sources Science and Technology, Vol. 26, No. 11, 2017, p. 115008. https://doi.org/10.1088/1361-6595/aa902e

[13] Jelloian, C. C., Bendana, F. A., Wei, C., Spearrin, R. M., and Macdonald, M. E., "Simultaneous vibrational, rotational, and translational thermometry based on laser absorption of co in shock-induced non-equilibrium," AIAA Scitech 2021 Forum, American Institute of Aeronautics and Astronautics, Reston, Virginia, 2021, pp. 2021-0448. https://doi.org/10.2514/6.20210448.c1. URL https://arc.aiaa.org/doi/10.2514/6.2021-0448

[14] Hanson, R. K., Spearrin, R. M., and Goldenstein, C. S., Spectroscopy and Optical Diagnostics for Gases, Springer International Publishing, Cham, 2016. https://doi.org/10.1007/978-3-319-23252-2

[15] Lee, D. D., Bendana, F. A., Nair, A. P., Pineda, D. I., and Spearrin, R. M., "Line mixing and broadening of carbon dioxide by argon in the v3 bandhead near $4.2 \mu \mathrm{m}$ at high temperatures and high pressures," Journal of Quantitative Spectroscopy and Radiative Transfer, Vol. 253, 2020, p. 107135. https://doi.org/10.1016/j.jqsrt.2020.107135.

[16] Rothman, L., Gordon, I., Barber, R., Dothe, H., Gamache, R., Goldman, A., Perevalov, V., Tashkun, S., and Tennyson, J., "HITEMP, the High-Temperature Molecular Spectroscopic Database," Journal of Quantitative Spectroscopy and Radiative Transfer, Vol. 111, No. 15, 2010, pp. 2139-2150. https://doi.org/10.1016/j.jqsrt.2010.05.001

[17] Nair, A. P., Lee, D. D., Pineda, D. I., Kriesel, J., Hargus, W. A., Bennewitz, J. W., Danczyk, S. A., and Spearrin, R. M., "MHz laser absorption spectroscopy via diplexed RF modulation for pressure, temperature, and species in rotating detonation rocket flows," Applied Physics B, Vol. 126, No. 8, 2020, p. 138. https://doi.org/10.1007/s00340-020-07483-8 URL https://link.springer.com/10.1007/s00340-020-07483-8.

[18] Nair, A. P., Jelloian, C. C., Kuenning, N. M., Minesi, N. Q., and Spearrin, M., "RF-waveform optimization for MHz-rate DFB laser absorption spectroscopy in dynamic combustion environments," AIAA Scitech 2022 Forum, American Institute of Aeronautics and Astronautics, 2022.

[19] Campbell, M. F., Owen, K. G., Davidson, D. F., and Hanson, R. K., "Dependence of Calculated Postshock Thermodynamic Variables on Vibrational Equilibrium and Input Uncertainty," Journal of Thermophysics and Heat Transfer, Vol. 31, No. 3, 2017, pp. 586-608. https://doi.org/10.2514/1.T4952

[20] Simpson, C. J. S. M., and Chandler, T. R. D., "A shock tube study of vibrational relaxation in pure CO2 and mixtures of CO2 with the inert gases, nitrogen, deuterium and hydrogen,” Tech. rep., 1970. 